\title{
Políticas socioambientais brasileiras e o aprendizado de uma nova ação
}

\section{Brazilian Socio-Environmental Policies and the Learning of a New Action}

\author{
Anderson Eduardo Silva OLIVEIRA*
}

\begin{abstract}
RESUMO
A partir da análise de três políticas socioambientais implementadas no Brasil (Política Nacional de Meio Ambiente, Política Nacional de Recursos Hídricos e Política Agrícola), o presente estudo apresenta as características e o modus operandi da formulação e da implementação dessas três políticas e discute a importância das mesmas para a construção da democracia no país. O estudo evidencia os avanços, assim como as limitações e dificuldades encontradas. Ao discutir tais questões, o estudo aborda a permuta entre o desenvolvimento das políticas socioambientais e o estabelecimento da democracia no Brasil.
\end{abstract}

Palavras-chave: democracia; política pública; políticas socioambientais.

\begin{abstract}
From the analysis of three socio-environmental policies implemented in Brazil (National Environment Policy, National Water Resources Policy and Agricultural Policy) this study introduces an analysis of the characteristics and modus operandi of the formulation and implementation of three Brazilian socio-environmental policies, as well as discusses their importance to the construction of democracy in the country. The study shows the advances, limitations and difficulties encountered. When discussing such matters, this study addresses the exchange between the development of socio-environmental policies and the establishment of democracy in Brazil.
\end{abstract}

Key-words: Democracy; public policy; socio-environmental policies.

\section{Introdução}

Existem diversas definições para o termo política pública (PARSONS, 1995). Dye (1984) considerou política pública como tudo aquilo que o governo decide ou não fazer. Já Nagel (1980) considerou que políticas públicas são "decisões governamentais destinadas a resolver problemas sociais". Para Machado (2003a), política pública é o conjunto de orientações e ações de um governo com vistas ao alcance de determinados objetivos, com interferência na atividade econômica, por meio de instrumentos

\footnotetext{
* Biólogo, doutor em Meio Ambiente pela Universidade do Estado do Rio de Janeiro (UERJ). Atualmente é Líder de Processo e Gerente de Projetos da Habtec Engenharia Ambiental. E-mail: aoliveir23@gmail.com
} 
de controle. Com o amadurecimento do processo de fazer política pública, surgiram ramificações e especializações. Dentre as quais, as políticas socioambientais. Assim, no âmbito do presente estudo, adotou-se o conceito de Santilli (2005), que considera políticas socioambientais as políticas públicas que fundamentam-se nos princípios do socioambientalismo e objetivam atender simultaneamente aos problemas sociais, ambientais, econômicos, tecnológicos e culturais da sociedade.

A partir da análise de três políticas socioambientais implementadas no Brasil, o presente estudo discute os processos envolvidos e a importância destas políticas para a construção da democracia no país. O presente estudo apresenta a análise das características e do modus operandi da formulação e da implementação de três políticas socioambientais brasileiras: (i) Política Nacional de Meio Ambiente; (ii) Política Nacional de Recursos Hídricos e (iii) Política Agrícola, com vias a estabelecer um referencial comparativo voltado ao aprimoramento da implementação de políticas socioambientais no Brasil.

\section{Caracterização de três políticas públicas}

\section{Política Nacional de Meio Ambiente}

A política ambiental pode ser discutida enquanto movimento que envolve o poder público e os demais interessados, objetivando conciliar o desenvolvimento e a conservação, ou enquanto instrumento normativo nacional, sendo assim um conjunto de grandes linhas de orientação estabelecidas para traçar o "caminho ambiental" do país. A existência de uma política formalizada por meio de um instrumento legal não elimina a existência da política ambiental enquanto movimento de forças, especialmente no caso da Política Nacional de Meio Ambiente (PNMA) brasileira, cuja construção é resultante do jogo de poderes e interesses sociais, econômicos e políticos da mais ampla gama de atores.

A instituição da Política Nacional de Meio Ambiente valeu-se enormemente do momento político nacional favorável em que o país caminhava para uma transformação significativa de um regime político militar ditatorial em direção a uma democracia (DIAS, 2006; MELLO, 2008). Nesse momento, as alianças deram-se por razões, muitas vezes, improváveis. Por exemplo, os interesses de alguns servidores públicos de instituições ambientalistas, como a Secretaria Especial de Meio Ambiente (SEMA), convergiam com o interesse coletivo de diversas outras instituições que buscavam ampliar o seu poder decisório e legitimar-se no cenário de governança nacional. Adicionalmente, houve grande apoio internacional por causa das discussões iniciadas durante a The United Nations Conference on the Human Environment e a crescente preocupação com a perda de florestas tropicais (SANTILLI, 2005).

Críticos ao processo de formulação da PNMA destacam que a Conferência concentrou-se demasiadamente nos efeitos da degradação, em detrimento do entendimento de suas causas (ex.: MACHADO, 2000), o que se tornou evidente nas propostas consideradas desenvolvimentistas que centravam-se nos modelos de sociedades capitalistas. Consequentemente, um dos mais relevantes pontos emergentes à época e expresso na Lei n ${ }^{\circ} 6.938 / 1981$ foi a avaliação de impactos ambientais (MACHADO, 2001). Entretanto, Viola (2002), ao analisar a mesma fase, apresenta uma interpretação diametralmente oposta, argumentando que a posição do país não era de um desenvolvimentismo radical. Tal fato o habilitou a uma posição de liderança na negociação de processos relevantes atualmente, como da Convenção de Mudança Climática. É bem verdade que, alinhada com princípios menos ortodoxos advogados internacionalmente, a Política apresentou objetivos ambiciosos, ao propor-se a compatibilizar o desenvolvimento socioeconômico à qualidade ambiental e à estabilidade ecológica (BRASIL, 1981), culminando então no conceito, ainda hoje questionável, de desenvolvimento sustentável. Mas, ao discutirmos os fundamentos da PNMA, devemos relembrar que essencialmente os danos ambientais relacionam-se com o desenvolvimento e com a realização de atividades antrópicas, relacionadas direta ou indiretamente com os sistemas produtivos. Por isso, não há como distinguir a manutenção da qualidade socioambiental da gestão dos efeitos da implantação de empreendimentos e da realização de atividades econômicas.

Rascunhada pelo corpo técnico da SEMA, a Política tornou-se a pedra fundamental para a regulamentação nacional da questão ambiental, ao instituir objetivos, responsabilidades e subsidiar a formulação de um glossário sobre o tema (DRUMMOND; BARROS-PLATIAU, 2006), até então distante do cotidiano do cidadão comum.

A PNMA apresentou grandes dificuldades para se firmar no cenário nacional. Em grande parte, essas dificuldades decorrem do processo paradoxal de sua formulação. Uma política nacional que interfere na dinâmica de todos 
os setores sociais e econômicos do país caracteriza-se por sua transversalidade. Por isso, deveria incluir na etapa de formulação alguns agentes primordiais que representam os interesses dos setores produtivos do país (ACSELRAD, 2001). Tais agentes, em sua maioria, foram incluídos no processo somente a partir da fase de implementação, quando fundamentos, princípios e instrumentos já haviam sido definidos, ainda que passíveis de mudanças (ACSELRAD, 2001; SANTILLI, 2005). Reforça-se então a tese de que são conhecimentos diferentes que subsidiam a formulação dos argumentos e ideias que, a partir de conflitos e disputas, permitem construir instrumentos normativos mais adequados às múltiplas visões da sociedade, culminando assim em um estado democrático de direito. Da etapa do processo de formulação da PNMA, extrai-se então um importante aprendizado: a necessidade de inclusão da maior parte de atores importantes, inclusive e principalmente aqueles que se opõem ou são críticos severos à sua formulação.

A PNMA estabeleceu os instrumentos de gestão, merecendo destaque a criação do Sistema Nacional do Meio Ambiente (SISNAMA), que permitiram a organização do arcabouço institucional existente. No contexto institucional, merece destaque também a instituição do Conselho Nacional do Meio Ambiente (CONAMA), instância decisória colegiada integrada por diversos ministérios setoriais, governos estaduais, Distrito Federal, Confederações Nacionais de Trabalhadores na Indústria, no Comércio e na Agricultura dentre outros (BRASIL, 1981; DRUMMOND; BARROS-PLATIAU, 2006).

Dos instrumentos estabelecidos pela PNMA, são especialmente importantes, para o presente estudo, aqueles que apresentam interface com a promoção da democracia, no processo de implementação das políticas socioambientais brasileiras, representados pelos mecanismos que garantiam a disponibilização das informações e a discussão sobre as possíveis soluções ambientais, no âmbito de arenas de discussão, como as audiências públicas e o CONAMA.

As primeiras décadas de vida da Política Nacional de Meio Ambiente registram a instalação e a evolução da primeira arena de debate da questão ambiental, o Conselho Nacional de Meio Ambiente (CONAMA). Num primeiro momento, o CONAMA postou-se como formulador e implementador das políticas ambientais do governo federal, garantindo unidade e coerência nas ações. Entretanto, a sua evolução tornou-o uma arena para disputas intragovernamentais e extragovernamentais, seguida pelo esvaziamento das funções, com a concentração na discussão de termino- logias, conceitos e normas que culminou na tecnificação da entidade (CAPOBIANCO, 1997; DRUMMOND; BARROS-PLATIAU, 2006).

Especialmente em seus primeiros anos de vida, o CONAMA, juntamente com as arenas instáveis e temporárias estabelecidas a partir de temas e projetos polêmicos (ex.: a construção de grandes hidrelétricas na Amazônia e a liberação de produtos transgênicos no mercado nacional), representou uma das mais importantes arenas nacionais para as disputas em torno da implementação da PNMA. O período foi marcado pela experimentação do estado de democracia, de conflitos e disputas interinstitucionais em torno das ideias e dos interesses (DRUMMOND; BARROS-PLATIAU, 2006). Esses autores destacaram também a multissetorialidade como uma das características intrínsecas às políticas socioambientais brasileiras, apesar desta ser uma característica ainda emergente. Há uma tendência natural de que, em áreas como a ambiental, ocorram conflitos por causa das transversalidades do tema em relação aos demais interesses e atividades antrópicas, como também foi verificado por Aicher e Diesel (2004), ao analisarem as políticas ambientais europeias.

Na avaliação de Machado (2001, p. 101), o período de transição democrática trouxe poucos avanços na política ambiental na esfera federal. Mas esta avaliação pode ser considerada demasiadamente superficial, especialmente se observarmos que o período também foi marcado pela reestruturação institucional, que obviamente dificultou a implementação de ações concretas, mas garantiu a viabilidade da implementação dos programas que vieram nos anos seguintes (BANERJEE; MACPHERSON; ALAVALAPATI, 2009; MEDEIROS, 2003; MELLO, 2008; SORRENSEN, 2009). Por exemplo, houve a criação do Ministério do Desenvolvimento Urbano e Meio Ambiente, posteriormente transformado em Ministério do Meio Ambiente, dos Recursos Hídricos e da Amazônia Legal, e a fusão de diversas instituições cujas missões se sobrepunham (MEDEIROS, 2003; 2006).

Estudos que analisaram o arcabouço institucional responsável pela implementação da PNMA, em geral, destacaram a carência de recursos humanos e financeiros como principais fatores limitantes ao alcance dos objetivos almejados (BANERJEE; MACPHERSON; ALAVALAPATI, 2009; BORGES et al., 2007; SORRENSEN, 2009). Mas, documentam-se ainda os efeitos da sobreposição de funções institucionais, fenômeno já documentado por outros autores (COSTA, 2008; MONOSOWSKI, 1989; 
SANTILLI, 2005). Tal característica foi evidenciada também em outras duas políticas analisadas por este estudo. No cotidiano, a superação de muitos desses problemas foi viabilizada pelas relações interinstitucionais não formais, que compartilhavam de dificuldades semelhantes, mas que, na maioria dos casos, não é documentada e só de viável identificação através de métodos não empregados para o desenvolvimento do presente estudo, por exemplo, entrevistas diretas.

Um novo momento foi estabelecido nas últimas duas décadas, sendo marcado pelas ações de dois principais governos. O governo Fernando Henrique Cardoso (19952002) foi considerado por Mello (2008) como contraditório. Isso porque o posicionamento nacional e as orientações expostas à comunidade internacional diferiam daquela praticada na esfera doméstica. O período caracteriza-se também por uma mudança nos planos e projetos, especialmente se comparado com aqueles praticados nos governos anteriores. Dentre essas mudanças, pode-se destacar a inclusão da dimensão ambiental no modelo de desenvolvimento nacional, tendo como um dos exemplos o zoneamento ecológico-econômico. Apesar de tais mudanças persistirem na dinâmica de substituição de cada governo, o eixo central foi mantido graças à existência de uma política instituída por um instrumento legal, o que pode ser ilustrado pela manutenção e ampliação de programas de proteção de florestas, iniciados nos governos anteriores (BANERJEE; MACPHERSON; ALAVALAPATI, 2009; SANTILLI, 2005). Já o governo Luiz Inácio Lula da Silva (2002 - 2010) adotou o discurso da transversalidade, do controle social, do desenvolvimento sustentável e do fortalecimento setorial, estatizando o discurso "socioambiental". O discurso inicial refletia o conjunto de alianças estabelecidas para garantir a vitória da eleição presidencial. Com a incorporação dos aspectos sociais, houve uma segunda onda de mobilização e participação pública na vida do país (MELLO, 2008). Apesar dos muitos retrocessos e dos poucos avanços, a ideia e os fundamentos da PNMA estão disseminados na sociedade e são mantidos pela legislação, apesar dos constantes ataques políticos ao arcabouço existente (ex.: ÉBOLI, 2008; O GLOBO, 2009). A PNMA está fortemente estruturada pelos seus instrumentos, instituições, arcabouço legal, pelo sistema e pelos subsídios científicos fornecidos pelas instituições de pesquisa. No entanto, a existência desses elementos, por si só, não garante sua efetividade ou eficiência, demandando assim permanente monitoramento, avaliação e aprimoramento dos elementos estruturantes. Quase três décadas após a sua regulamentação, alguns dos instrumentos da Política não foram sequer efetivamente implementados. Por exemplo, o Relatório de Qualidade do Meio Ambiente, que deveria permitir à sociedade saber as condições em que vive, sofreu completo esvaziamento. Os relatórios emitidos espaçadamente nunca conseguiram alcançar seus objetivos porque sua divulgação e circulação restringiam-se à própria instituição geradora, o IBAMA. O esforço para mudar essa situação foi empreendido com a transformação do mesmo em uma revista eletrônica que só se materializou em um volume, no ano de 2007 (IBAMA, 2007).

Uma das mais relevantes oportunidades perdidas pela PNMA foi o esvaziamento da arena de discussões do CONAMA, que poderia garantir que ideias e opiniões divergentes pudessem ser colocadas em disputa na escala nacional. Como resultado, desde então, todas as disputas passaram a ocorrer de maneira pontual e pulverizada, diferentemente do que aconteceu com a Política Nacional de Recursos Hídricos, como veremos mais adiante.

Por outro lado, a PNMA contribuiu para a legitimação dos conceitos e fundamentos científicos perante a população. Além disso, as instituições responsáveis pela implementação da Política (ex.: MMA, IBAMA, Secretarias Estaduais de Meio Ambiente e ONGs) puderam melhorar sua posição e sua legitimidade por meio de seu posicionamento em questões relativas ao meio ambiente, sobretudo ao enfrentar, em nome do interesse comum, interesses em um estado exclusivamente desenvolvimentista.

Apesar das deficiências, cinco pontos definem, em resumo, resultados críticos obtidos com a implementação da PNMA: (i) a introdução da questão ambiental nos programas e políticas econômicas do governo, cujo exemplo mais significativo é o Protocolo Verde; (ii) a formulação de uma Política Nacional Integrada para a Amazônia Legal, com vistas à reorientação do crescimento econômico na região, a sua maior integração interna e externa e à valorização do homem amazônico; (iii) a aceleração da internalização dos recursos externos direcionados à proteção da biodiversidade nacional; (iv) o preparo do ambiente para a implantação de um modelo de gestão descentralizada e compartilhada dos recursos hídricos; (v) a implementação e manutenção dos inventários de biodiversidade nacional, como, por exemplo, o Programa Nacional de Diversidade Biológica (PRONABIO) e o Projeto de Conservação e Utilização Sustentável da Diversidade Biológica Brasileira (PROBIO).

Ao reestruturar o sistema ambiental brasileiro, a PNMA serviu também de alicerce para o desenvolvimento 
de políticas setoriais, como, por exemplo, a Política Nacional de Recursos Hídricos, que será discutida a seguir. Ainda que permaneçam alguns desalinhamentos entre a conduta das instituições e a legislação, a PNMA estabeleceu importantes referenciais para a sociedade brasileira.

\section{Política Nacional de Recursos Hídricos}

Noque se refere à Política Nacional de Recursos Hídricos (PNRH), o principal aspecto aplicável diz respeito ao sistema de gestão instituído pela lei que, em seu fundamento VI e em sua diretriz IV, previu que o planejamento e a gestão dos recursos hídricos deveriam ser descentralizados e contar com a participação do Poder Público, dos usuários e das comunidades (BRASIL, 1997a). Para isso, os Comitês de Bacia tornaram-se as arenas de discussão e decisão. Simultaneamente, veremos a importância dos Planos de Recursos Hídricos como instrumento de implementação dessa política.

Esta política tornou-se um marco para a gestão no Brasil, por tratar de um bem de valor peculiar para o país, como será brevemente descrito a seguir. O Brasil possui aproximadamente $12 \%$ da água doce disponível no mundo e 53\% da água doce do continente sul-americano. Ainda assim, apresenta sérios problemas de disponibilidade de água por causa da distribuição e da demanda heterogênea do recurso em seu território. Por exemplo, em alguns Estados, como Pernambuco, Paraíba, Sergipe, Alagoas e Rio Grande do Norte, a disponibilidade de água por habitante ao ano varia entre $500 \mathrm{~m}^{3} /$ habitante/ano e $1.000 \mathrm{~m}^{3} /$ habitante/ano. Além disso, a água, como recurso hídrico, é fundamental ao desenvolvimento de quase todas as atividades econômicas, fato que é reconhecido como um dos causadores do histórico nacional de gestão fragmentada e centralizada de águas. A gestão era fragmentada porque cada setor, por exemplo, energia elétrica, agricultura irrigada e saneamento, realizava seu próprio planejamento e, consequentemente, adotava as medidas mais adequadas exclusivamente aos seus interesses. Simultaneamente, era centralizada porque os governos, estaduais e federal, definiam suas prioridades sem avaliá-las com os governos municipais, os outros usuários da água e a sociedade civil (ABERS; JORGE, 2005; IORIS, 2008).

Antes da instituição da PNRH, seu uso era regido por diversas normas e códigos concorrentes e/ou conflitantes, cuja execução era realizada por uma estrutura institucional ineficaz (MILARÉ, 2007). Foram realizadas várias tentativas de formulação de uma política nacional de recursos hídricos e de um modelo mais adequado de gestão da água, iniciados com a realização de seminários, congressos e comissões parlamentares. Reconhecendo a variedade de condições e problemas relacionados à disponibilidade e à demanda de recursos hídricos, a Associação Brasileira de Recursos Hídricos (ABRH) alertou que a água era um bem econômico passível de tornar-se fonte de intensos conflitos e recomendou que fosse promovida a participação pública e a descentralização para a adequada gestão (ABRH, 1995). Considerando então a necessidade de prover adequada gestão, o Congresso Brasileiro, ao instituir a Constituição Federal de 1988, tornou responsabilidade do governo federal a implementação de um Sistema Nacional de Gestão de Recursos Hídricos que garantisse o adequado planejamento, regulamentação, controle do uso, preservação e recuperação dos recursos hídricos no país (PORTO; PORTO; AZEVEDO, 1999). Mas a Carta Magna demandou, expressamente, a descentralização da gestão da água entre os entes da federação (BRASIL, 1988).

Em 1991, o Estado de São Paulo tornou-se o primeiro a aprovar sua lei de recursos hídricos, sendo seguido por outros 14 estados que, entre 1991 e 1997, criaram legislações sobre recursos hídricos. Em muitos casos, tais instrumentos eram semelhantes à lei paulista que, por sua vez, baseava-se na lei das águas francesas (MACHADO, 2003b), com a criação de comitês participativos de bacia hidrográfica e da cobrança pelo uso da água. Ainda em 1992, em Dublin, realizou-se a The Dublin Statement on Water and Sustainable Development, convenção que formulou quatro princípios para a gestão sustentável da água, dos quais dois estabeleceram-se como critérios básicos para a gestão de recursos hídricos em quase todos os países do planeta, inclusive o Brasil. O primeiro foi de que a água é um recurso finito e vulnerável, essencial para a manutenção da vida, do desenvolvimento e do meio ambiente. O segundo é de que a água tem valor econômico para todos os seus usos e deve ser considerada como um bem econômico (HESPANHOL, 2008; UNITED NATIONS ORGANIZATIONS - UNO, 2009). Os princípios adotados no Brasil não foram a única parte da política inspirada na experiência internacional; grande parte da estrutura organizacional da gestão brasileira de recursos hídricos é uma transposição do modelo francês (FORMIGA-JOHNSSON; KEMPER, 2005a; HUBERT; PEREIRA; LANNA, 2002; LANNA; PEREIRA; HUBERT, 2002; MACHADO, 2003b).

Uma extensiva revisão dos instrumentos normativos existentes e do sistema de gestão de recursos hídricos 
iniciou-se em 1986 e subsidiou a formulação da proposta, que começou a tramitar no Congresso no início da década de 1990, por meio do Projeto de Lei n ${ }^{\circ} 2.249 / 1991$. O texto submetido ao Congresso foi elaborado por uma força-tarefa criada pela Presidência do Brasil, a partir de inúmeras consultas públicas e seminários, organizados por universidades, agências governamentais e não governamentais (AGÊNCIA NACIONAL DE ÁGUAS - ANA, 2002; 2006). Ao contrário do processo de formulação da PNMA, houve intensa validação da formulação da PNRH por meio da inserção de diferentes grupos de interesse. Tanto durante a elaboração do projeto de lei quanto durante os seus ajustes e votação no Congresso, houve grande colaboração de partes estatais e não estatais interessadas no resultado final (ANA, 2002; 2006; BRASIL, 1997a; MMA, 2006).

A Política Nacional de Recursos Hídricos foi aprovada na Câmara dos Deputados em outubro de 1996 e no Senado Federal em dezembro do mesmo ano (ABERS; JORGE, 2005; LUCHINI; SOUZA; PINTO, 2003; PORTO; PORTO; AZEVEDO, 1999). Ao final, a Lei no 9.433/1997 instituiu a Política Nacional de Recursos Hídricos (PNRH), também conhecida como a "Lei das Águas". Depois da aprovação dessa lei, todos os estados deram início à elaboração de suas políticas de recursos hídricos (ABERS; JORGE, 2005; ANA, 2006).

A PNRH tem por objetivo promover a utilização sustentável dos recursos hídricos e a prevenção contra os eventos hidrológicos nocivos. Assim, objetivando a sustentabilidade hídrica, essa política, em seu artigo $2^{\circ}$, tornou imprescindível a obtenção de outorga, sendo concedida somente pelo poder público aos usuários cuja utilização almejada for compatível com o plano da bacia hidrográfica. Portanto, a outorga é um importante instrumento de planejamento, monitoramento e fiscalização dos recursos hídricos. Já a prevenção e a defesa contra os eventos hidrológicos nocivos, por exemplo, inundações, enchentes e desmoronamentos, se dão também por meio da ordenação do território da bacia. Grande parte desses eventos são previsíveis e evitáveis, pois são decorrentes da ação humana, por exemplo, ocupação desordenada do solo, poluição e supressão da mata ciliar (ANA, 2006; BRASIL, 1997a).

$\mathrm{O}$ artigo $1^{\circ}$ da Lei estabelece um dos pontos cruciais da gestão do recurso: a definição da unidade territorial de gestão - a bacia hidrográfica (BRASIL, 1997a). Essa também foi a unidade de gestão adotada por diversos outros países (FORMIGA-JOHNSSON; KEMPER, 2005a; 2005b). Assim sendo, a gestão tem como unidade de refe- rência a bacia hidrográfica e não as unidades geopolíticas definidas como entes federados. Hodiernamente, a maioria das políticas públicas ambientais adota a bacia hidrográfica como unidade territorial de planejamento e implementação (ARAÚJO; ROCHA; SILVA, 2007). O que essencialmente esse recorte espacial propõe é ajustar-se à escala do problema e dos atores que efetivamente estão envolvidos com a sua solução direta. A PNRH, em seu artigo $3^{\circ}$, traça as diretrizes gerais de ação da gestão hídrica, que têm por finalidade integrar e articular a gestão dos recursos hídricos com a gestão dos demais recursos naturais e do meio ambiente. Em linhas gerais, as diretrizes estabelecem que a gestão hídrica deveria ser integrada e articulada com a gestão ambiental, gestão do uso do solo, gestão dos sistemas estuarinos e zonas costeiras, e também com os planejamentos estadual, regional, nacional e dos setores usuários. Estabelece ainda que a gestão hídrica deve ser realizada sem dissociação dos aspectos quantitativos e qualitativos, haja vista que o uso dos recursos hídricos afeta ambos os padrões (BRASIL, 1997a).

Para sua plena implementação, a PNRH previu seis instrumentos, a saber: (i) os planos de recursos hídricos (planos de bacia hidrográfica, planos estaduais de recursos hídricos e o plano nacional de recursos hídricos); (ii) o enquadramento dos corpos de água em classes segundo os usos preponderantes; (iii) a outorga dos direitos de uso dos recursos hídricos; (iv) a cobrança pelo uso dos recursos hídricos; (v) a compensação aos municípios, e (vi) o sistema de informações sobre recursos hídricos. Face aos objetivos do capítulo, merecem especial destaque os planos de recursos hídricos (BRASIL, 1997b). Na implantação de cada um desses instrumentos, existem disputas que se dão nas esferas nacional e local, aí definida como a bacia hidrográfica. Os resultados dessas disputas não poderiam ser explicados de outra forma se não pelo entendimento das relações vistas no cotidiano das arenas, incluindo aquelas entre instituições e pessoas sem vínculos hierárquicos formais (ex.: FORMIGA-JOHNSSON; KEMPER, 2005b; LEMOS; OLIVEIRA, 2005; PORTO; PORTO, 2002).

Os planos de recursos hídricos visam fundamentar e orientar a implementação da PNRH e o gerenciamento dos recursos hídricos (PORTO; PORTO, 2002). A PNRH estabeleceu também o conteúdo mínimo indispensável dos planos e os tornou de ordem pública. Todos os planos de recursos hídricos deverão obrigatoriamente conter o prescrito. Expressamente, a PNRH coloca que um dos seus principais instrumentos, o plano de bacia, é um mecanismo 
de longo prazo, com horizonte de planejamento compatível com o período de implementação de seus programas e projetos. A confecção do plano é atribuição da agência de água e sua aprovação compete ao Comitê de Bacia. Antes dos planos serem apreciados e submetidos à votação do Comitê de Bacia, os mesmos deveriam ser amplamente publicados, para que a comunidade pudesse tomar ciência de seu conteúdo e manifestar suas intenções (ANA, 2006). Mas essa etapa do processo de gestão de recursos hídricos ainda apresenta muitas falhas na sua implementação. Pela capacidade de limitar ou proibir determinadas atividades, os Comitês de Bacia deveriam ser ambientes de intensas negociações que incorporariam aspectos científicos, técnicos e sociais. Mas, como documentado por Formiga-Johnsson e Kemper (2005a, p. 37), em alguns casos (ex.: Comitê de Bacia Hidrográfica do Alto Tietê), o governo estadual ainda mantém uma postura centralizadora em muitas das discussões dos grandes projetos. Em parte, tal posição deve-se ao fato de que, em anos recentes, o comitê não conseguiu dar prosseguimento a decisões importantes para a bacia, como foi ilustrado pelo estudo de caso apresentado por Formiga-Johnsson e Kemper (2005a).

A PNRH estabeleceu uma profunda mudança valorativa no que se refere aos usos múltiplos da água. Além disso, estabeleceu-se um importante precedente para a participação popular da sua gestão. Em grande parte, o interesse e o envolvimento popular decorreram da importância deste recurso à sobrevivência humana, assim como das demais espécies, e sua relevância para todos os processos produtivos humanos, quer seja comercial, industrial, agrícola, recreativo ou esportivo. Em decorrência, um dos pilares da PNRH é a gestão dos recursos hídricos visando aos usos múltiplos, ou seja, uso urbano, industrial, geração de energia elétrica, navegação, lazer e irrigação. Ao contrário da PNRH, o Código de Águas, vigente até então, conferia prioridade à produção energética em detrimento dos demais usos (LUCHINI; SOUZA; PINTO, 2003; MACHADO, 2003a; 2003b; 2006; MILARÉ, 2007). Por essas mesmas razões, a PNRH é objeto de amplos e numerosos estudos acadêmicos.

A Lei $n^{\circ} 9.433 / 1997$, assim como os instrumentos legais estaduais, reflete a profunda mudança na concepção do manejo dos recursos naturais, sobretudo se comparada à forma pela qual os mesmos vinham sendo anteriormente tratados pelo poder público (ABERS; JORGE, 2005; ABERS; KECK, 2009; MACHADO, 2003a). Ao desenvolver o presente estudo, verificou-se que três questões sobre a PNRH demandam ser explicitadas aqui e discutidas ao longo do item. A primeira diz respeito à concepção dos recursos hídricos como bem público, consequentemente, deve ser compartilhada com o propósito de atender aos interesses coletivos de toda a população. A segunda consideração está vinculada à constatação de que os usos da água envolvem por vezes uma interação conflituosa entre um conjunto significativo de interesses sociais diversos. A terceira consideração relaciona-se à construção de um arcabouço jurídico-institucional que, reconhecendo a legitimidade de tais interesses, estabelece um processo de gestão de recursos hídricos que permite contemplar seu uso múltiplo, não favorecendo uma determinada atividade ou um determinado grupo social.

Considerando a relevância da participação pública para o seu sucesso, a PNRH adotou como um de seus fundamentos a gestão descentralizada e participativa que, na opinião de Porto, Porto e Azevedo (1999), é induzida pela instalação de níveis inferiores de decisão, reunindo todos aqueles com interesses no recurso. A gestão é descentralizada porque realizada em nível de bacia hidrográfica, por meio dos comitês de bacia, ou seja, a gestão não é realizada em nível estadual ou federal. É participativa, posto que a lei prevê que a gestão não se realizará somente por órgãos públicos, mas também pelos usuários e organizações civis (MACHADO, 2003b; MACHADO; MIRANDA; PINHEIRO, 2004). Assim, a forma de gestão preconizada pela PNRH estabeleceu um importante precedente para a concepção e para a implementação da gestão de recursos naturais no Brasil. A principal estratégia para a gestão participativa passou a ser o estabelecimento de parcerias entre o poder público, usuários e a sociedade civil, que incluíram numerosos conselhos e/ou comissões nacionais, estaduais e locais (MACHADO; MIRANDA; PINHEIRO, 2004). Mesmo considerando que muitos dos comitês de bacia ainda não tenham plena capacidade de gestão e decisão por estarem submetidos a uma forte intervenção estatal, a partir do momento em que eles se tornaram responsáveis pela aprovação do plano de bacia, passaram a ampliar seu poder decisório.

O formato de gestão descentralizado não implica na inexistência de um órgão de referência nacional para a gestão do recurso. Pelo contrário, o mesmo fundamento explicita que a gestão deve contar com a participação do Poder Público, sem discriminar a esfera. Para tanto, instituiu-se por meio da Lei ${ }^{\circ}$ 9.984, de 17 de julho de 2000, a Agência Nacional de Águas (ANA), que é uma autarquia com autonomia administrativa e financeira, vinculada ao 
Ministério do Meio Ambiente (BRASIL, 2000). A ANA é uma agência gestora de um recurso natural e não uma agência reguladora da prestação de serviços públicos, o que a diferencia fundamentalmente das demais agências existentes (MACHADO, 2003a). No contexto de gestão, a principal atuação da ANA inclui: supervisionar, controlar e avaliar as ações e atividades decorrentes do cumprimento da legislação federal hídrica; disciplinar, em caráter normativo, a implementação, a operacionalização, o controle e a avaliação dos instrumentos da PNRH; o planejamento e a promoção de ações destinadas a prevenir ou minimizar os efeitos de secas e inundações; implementação do Sistema Nacional de Informações sobre Recursos Hídricos; fomentar a pesquisa e a capacitação de recursos humanos para a gestão dos recursos hídricos e, ainda, prestação de apoio aos estados na criação de órgãos gestores de recursos hídricos (BRASIL, 2000).

Os comitês tornaram-se um dos pilares da implementação da PNRH. Ao analisar os fundamentos e as consequências da descentralização pública, Abers e Keck (2009) pontuaram que os conflitos são inerentes aos processos decisórios, onde múltiplas opiniões são expostas. A partir de uma profunda revisão da literatura especializada, esses autores destacaram a existência de diversas opiniões sobre as consequências da descentralização, dentre as quais, a possibilidade de redução de custos de transação, melhor aproveitamento de informações e maior capacidade de adaptação às necessidades locais.

A transição do regime de gerenciamento centralizado burocrático para um sistema participativo descentralizado, como ocorreu com a gestão de recursos naturais, especialmente dos recursos hídricos na década de 1990, apresenta um feito altamente político, envolvendo consigo lutas por poder e influência durante todo o período de reorganização institucional. A literatura científica sobre o tema destaca ainda a tendência de o processo favorecer a redefinição do papel de poder em que se situam os especialistas na gestão dos recursos, aumentando a importância da ampliação das relações interpessoais na garantia do alcance dos interesses. Ainda que este processo valorize aspectos não técnicos e, em alguns casos, aspectos interpessoais ao processo decisório, algumas vantagens são documentadas. Dentre elas, aponta-se a redução dos riscos de corrupção, limitação do grau de liberdade de condutas abusivas e de exercício discricionário do poder por parte do executivo, uma vez que a responsabilidade passa a ser dividida por uma gama maior de atores. Mas o ideal seria a implementação de uma efetiva prática de gestão pública colegiada e integrada (MACHADO, 2003b). Há necessidade de se adotar uma perspectiva crítica da compreensão da governança de recursos, neste caso os hídricos, como um instrumento de política supostamente neutro. Apesar da retórica, as abordagens idealizadas e instrumentais de governança de recursos hídricos tendem a negligenciar a existência de divisões sociais fundamentais, que são principais condutores de conflitos deste recurso (CASTRO, 2007).

Há uma corrente de pensamento que argumenta que este processo de descentralização não foi fruto apenas das manifestações das décadas que antecederam à formulação da PNRH, mas, sim, de parte de um projeto neoliberal de estado mínimo, surgido no Brasil a partir de 1989, integrante da estratégia de implementação do ajuste neoliberal, que se isenta progressivamente de suas responsabilidades sociais e as transfere para a sociedade civil (ex.: COSTA, 2008, p. 27). Por outro lado, o mesmo fenômeno é visto por outros autores como uma otimização da máquina estatal e uma redução da burocracia (ex.: BRESSER-PEREIRA, 1999).

Análises de autores como Costa (2008) e Sousa (2005) ressaltaram a existência de dificuldades iniciais para a implementação dessa metodologia descentralizadora, por causa da existência de um passado de centralização e de hegemonia de determinados polos regionais. Além disso, um comportamento usualmente observado nos comitês já em operação no Brasil é que o processo decisório torna-se mais complexo e demorado (PORTO; PORTO; AZEVEDO, 1999). Ademais, alguns autores argumentaram que a descentralização não necessariamente garante por si só maior eficiência e/ou mais democracia no processo decisório (ex.: COSTA, 2008; FORMIGA-JOHNSSON; KEMPER, 2005b).

A literatura científica brasileira documenta diversos casos em que a eficiência dos comitês pode ser prejudicada, principalmente em duas circunstâncias. Na primeira, quando instituições locais não têm capacidade técnica ou administrativa de deliberar ou executar efetivamente. Na segunda, quando os interesses políticos locais são caracterizados por clientelismo, corrupção ou outros padrões que fazem com que as decisões políticas não sigam as prioridades técnicas (ex.: COSTA, 2008; FORMIGA-JOHNSSON; KEMPER, 2005b; IORIS, 2008; 2009; LUCHINI; SOUZA; PINTO, 2003; PORTO; PORTO, 2002; PORTO; PORTO; AZEVEDO, 1999).

Por causa do seu caráter multi-institucional, os comitês de bacias hidrográficas deveriam possibilitar e garantir um efeito catalisador, estimulador e de intercâmbio entre 
todos os agentes que atuam na preservação, no controle e na recuperação dos recursos hídricos. Para isso, precisariam estar muito bem sistematizados e disponibilizados para os membros do comitê e traduzidos para a população em geral. Os principais benefícios advindos dessas práticas participativas seriam o acesso da população na definição da prioridade de alocação de recursos públicos e o fato de a sociedade civil poder exercer um papel mais efetivo de controle e fiscalização, ao atuar em conjunto com o Estado. Entretanto, o que se observa na prática são experiências participativas passando por desafios e, também, muita criatividade na busca de soluções (COSTA, 2008, p. 27).

As informações consolidadas pela presente análise nos permitem afirmar que a PNRH é objeto de diversas críticas, muitas delas muito bem fundamentadas. Entretanto, diversos estudos reconhecem as inovações positivas que essa política introduziu. Deve-se destacar o preconizado compartilhamento da gestão de recursos naturais que é, na implementação desta política, o que mais se aproxima de seu ideário no território nacional. A mobilização pública, a implementação dos comitês de bacia como lócus para o exercício da gestão, a descentralização da gestão e o arcabouço jurídico-institucional estão entre os principais fatores estruturantes dessa política. A superação de algumas resistências, decorrentes de práticas conservadoras em relação à gestão dos recursos hídricos, é que irá exigir dos comitês e de todos os segmentos envolvidos, quer sejam eles públicos ou privados, decisão política, um processo de educação para o exercício da cidadania, incluindo os princípios fundamentais da democracia e da ética, a predisposição ao diálogo e respeito aos espaços institucionais já constituídos, na busca de consensos para definição de estratégias conjuntas de ação em prol da bacia.

\section{Política agrícola}

No Brasil, a questão agrícola, necessariamente, perpassa por questões econômicas e de segurança social nacional, haja vista a sua representatividade como meio de vida direto e indireto para uma parcela expressiva da população. Dada a sua importância econômica, política e social, o Brasil instituiu, por meio da Lei $\mathrm{n}^{\circ} 8.171 / 1991$, a Política Agrícola. Essa política começou a tramitar no Congresso a partir do Projeto de Lei $n^{\circ} 4.086 / 1989$. A proposta visava atender ao disposto no artigo 187 da Constituição Federal, que tratava das políticas agrária e agrícola (BRASIL, 2009).
Ao voltarmos na linha do tempo, veremos que, em meados da década de 1960, na imagem de diversos países em desenvolvimento, o Brasil passou a adotar um modelo de modernização do setor agrícola que se tornou responsável pela transformação da agricultura no país. O modelo era fortemente marcado pela concentração de poder e intervenção estatal, que empregou a concessão de crédito rural, preços mínimos, assistência técnica e pesquisa como principais instrumentos para a modernização (CONCEIÇÃO; CONCEIÇÃO, 2005; TÁVORA, 2003). Entretanto, no final da década de 1980, houve uma drástica mudança no cenário, marcada pela redução de gastos orçamentários destinados aos programas de suporte à agricultura. Esta situação favoreceu o surgimento da Política Agrícola de 1991, devido ao esgotamento do setor (TÁ VORA, 2003). Nesta transição, o despreparo do país tornou-se evidente, ao registrar crises consecutivas. A sua consolidação foi então estimulada pelo estabelecimento de um novo ambiente institucional, com uma economia aberta aos mercados internacionais e menor atuação intervencionista do governo. Este novo cenário tem impacto direto sobre a agricultura nacional, que precisava galgar um novo patamar de competitividade (LOPES; LOPES; BARCELOS, 2007).

Segundo Dias (2006), esse processo de liberalização estendeu-se à maioria dos setores econômicos, como reflexo de um esforço do poder legislativo, empreendido no final da década de 1980, para ampliar a democracia e reduzir os poderes estatais. Em parte, esse fenômeno afetou também a dinâmica social do país, culminando em amplos movimentos sociais. Dentre estes, destaca-se a gestão descentralizada dos recursos hídricos e o neoliberalismo, discutidos anteriormente. Todavia, no caso da Política Agrícola, a descentralização não ocorreu de modo tão amplo, como será analisado mais adiante.

Pelo seu histórico de interfaces com a economia nacional, há uma volumosa literatura que trata das políticas de preços e comércio exterior, da política macroeconômica, das políticas de subsídios, incentivos e tributos, da política tecnológica e de sua interface com as políticas agrária e fundiária (ex.: CARVALHO; SILVA, 1993; CUNHA, 2004; DIAS, 2006; ELOBELD; BEGHIN, 2006). Existem ainda estudos que tratam das características gerais da Política Agrícola e do processo de sua formação e dos problemas da agricultura nacional (ex.: BALSAN, 2006; BRESSER-PEREIRA, 1964).

Os objetivos da Política Agrícola foram apresentados no $\operatorname{artigo} 3^{\circ}$ da Lei ${ }^{\circ} 8.171 / 1991$, destacando o planeja- 
mento, a promoção da equidade social e a conciliação com o desenvolvimento sustentável (BRASIL, 1991). Apesar do discurso vigente de descentralização, sob a ótica do planejamento em escala nacional e sua interface internacional, a Política Agrícola é mantida sob gestão quase exclusiva do governo federal. Tal fato é evidenciado pelos diversos elementos apresentados a seguir. O primeiro deles é identificado no primeiro objetivo listado pela Política. De acordo com este, cabe ao Estado o planejamento das ações. Com base nesse planejamento, o curso da Política é orientado pelo Conselho Nacional de Política Agrícola (CNPA), cujos membros são majoritariamente representantes do poder executivo federal. A este conselho cabe então articular, negociar, implementar os mecanismos, diretrizes e estratégias competitivas para as propostas de política agrícola, além de propor ajustamentos e alterações na política agrícola (BRASIL, 2003). A composição do CNPA concentra o poder decisório em instituições do governo federal ou organismos indicados por este. Assim, apesar de ser preconizada a paridade de poder entre os entes federados, estados e municípios não possuem espaço garantido no Conselho, cujo objetivo principal é planejar e orientar as ações relacionadas com o desenvolvimento agrícola nacional. A condução descrita contradiz o objetivo VI da Política, que trata da promoção da descentralização da execução do setor rural. De acordo com esse mesmo objetivo, cabe aos municípios e estados a execução da Política, adequando os diversos instrumentos às suas necessidades e realidades. Como posto, não há garantias desses entes na efetiva participação nas fases de planejamento e concepção (BRASIL, 1991).

O segundo elemento apresenta-se no objetivo que trata da compatibilização entre as ações da Política Agrícola e as ações para a reforma agrária. Para essa discussão, deve-se recorrer aos argumentos organizados por Dias (2006), que discutiu, entre outras questões, sobre os conflitos fundiários e o arcabouço legal existente. Em sua análise, o autor destaca o fato de que somente o governo federal tem poder para expropriar terras para fins de reforma agrária. Além disso, cabe também ao governo federal a incorporação das terras públicas ao patrimônio do setor privado. Assim, em um país com amplas fronteiras agrícolas, o mercado de terras apresenta uma estrutura em que a oferta de terras depende da política de um ente central, cuja morosidade na execução é reconhecida. Aqui, cabe destacar como uma das características da administração pública brasileira a dificuldade em executar o planejado.
A evolução desse cenário torna-se dramática por causa do desmonte das instituições responsáveis pela implementação das ações que subsidiariam a estruturação social do setor. Tal fato pode ser evidenciado pelos relatórios do Instituto Nacional de Colonização e Reforma Agrária (INCRA), que demonstram baixa execução por causa do quadro de funcionários deficitário e o emprego de recursos tecnológicos ultrapassados (INCRA 2009a; 2009b).

Pelas características acima descritas, poder-se-ia considerar que a Política Agrícola apresenta um caráter essencialmente estatal, enquadrando-se no conceito inglês policy, que corresponde a um conjunto de ações ou normas de iniciativa governamental, visando atingir determinados objetivos. Todavia, a Política Agrícola contemporânea apresenta um segundo viés, no qual nota-se que há um recuo acentuado do governo federal. Essas características são especialmente evidentes nas políticas agrícolas locais, sobretudo na elaboração de novas políticas públicas de desenvolvimento sustentável que se adequaram às premissas da Agenda 21. Essa situação reforça a argumentação de autores como Costa (2008), segundo os quais esse posicionamento evidencia uma isenção progressiva do governo federal de suas responsabilidades. Curiosamente, essas mesmas adequações decorrem das pressões oriundas dos compromissos dos acordos internacionais, cujo negociador nacional é o próprio governo federal.

Dentre os seus objetivos, a Política Agrícola expressamente demanda a proteção ao meio ambiente, garantia do seu uso racional e estímulo à recuperação dos recursos naturais. Ao se aprovar essa política, objetivos e estratégias voltados para a garantia da sustentabilidade se fazem presentes, garantindo assim a inserção do discurso do desenvolvimento sustentável na agenda política do setor agrícola (BRASIL, 1991). Evidentemente, uma política não funciona apenas com a destinação de créditos, mas de outros instrumentos, como o desenvolvimento da pesquisa agrícola que lhe dará suporte. Esses elementos tornaram-se especialmente importantes no caso das ações direcionadas aos pequenos agricultores que obtiveram acesso a tecnologias e a informações oriundas de pesquisas realizadas pela Embrapa. Nesse ínterim, tornou-se especialmente emblemático o Programa de Pesquisa em Sistemas de Produção da Agricultura Familiar (MELLO, 2008).

Nessa escala de análise, outros atores passam a destacar-se, que não o governo federal, especialmente aqueles resultantes do envolvimento dos próprios trabalhadores na 
defesa dos assuntos importantes para os mesmos. Em grupos organizados, passaram a pressionar os governos federal e estadual por políticas agrícolas específicas e para o acesso à terra, promovendo assim a reinserção da reforma agrária na agenda política, por meio dos projetos de assentamento e da criação do Programa Nacional de Fortalecimento da Agricultura Familiar (PRONAF) como fonte de crédito e assistência técnica (ALVES, 1993; MELLO, 2008). Do ponto de vista das políticas públicas, esta é uma das mais expressivas mudanças face ao histórico de privilégios às grandes propriedades voltadas para a monocultura de exportação, que recebiam estímulos e garantias e que deixavam à margem a produção voltada para o abastecimento interno. Simultaneamente, houve um aprimoramento do quadro institucional por meio do desenvolvimento da assistência técnica, juntamente com o surgimento das secretarias municipais de agricultura e a intensificação da participação não estatal, principalmente de ONGs, na década de 1990. Essa configuração estreitou a colaboração nas escalas local e regional, e simultaneamente ampliou as diferenças em escala nacional. As políticas públicas de apoio à agricultura familiar, especialmente o PRONAF, promoveram forte impacto, sobretudo nas regiões com maior apelo ecológico, como a amazônica e a pantaneira, seja pela diversidade dos atores apoiados, seja pela preocupação ambiental presente (MELLO, 2008; PORRO; SERRAO; CORNELIUS, 2005; SANTILLI, 2005).

Não há duas políticas públicas. A dicotomia observada é, na verdade, resultante do amplo espectro de questões ao qual propõe-se cobrir a Política Agrícola, reforçada ainda pelos aspectos que emergiram com a descentralização e a ampliação da participação de organizações sociais no final da década de 1980. Cada ramificação produz conhecimentos e oferece insights próprios que podem servir para entender distintas dimensões da realidade socioambiental. A Política Agrícola contemporânea, assim como as demais políticas aqui exploradas, não pode ser examinada exclusivamente por uma das óticas. Ainda que as decisões sejam institucionalizadas, o processo construtivo dessas decisões perpassa por relações não hierárquicas e, por vezes, não institucionalizadas.

Estudando o período inicial da implementação da Política Agrícola (década de 1990), Teixeira (2002) destacou a existência de entraves que se tornam críticos para o desenvolvimento da assistência técnica. Para o autor, a principal causa foi o reduzido volume de recursos financeiros, acompanhado pela falta de uma coordenação nacional às ações de cunho social. Neste contexto, destaca-se a necessidade da ampliação do acesso à informação, que pode ser considerado um dos pontos críticos à consolidação de políticas socioambientais (SANTILLI, 2005), haja vista a sua precariedade nacional. Como parte fundamental da tríade de sustentação de ações complexas, a geração e a difusão de conhecimentos sobre o objeto da política foram expressamente apresentadas no Capítulo IV, definindo a EMBRAPA como coordenadora da ação em escala nacional (BRASIL, 1991).

Apesar da importância institucional federal no desenvolvimento da Política Agrícola, atores locais são reconhecidamente de grande relevância para a mesma, especialmente na implementação das ações em escalas regional e local. A participação de atores não estatais vem crescendo, principalmente na etapa executiva. Em parte, a ampliação da participação desses atores resulta da maior interação entre a Política Agrícola e as demais políticas sociais e ambientais em implementação no país, porque buscam ampliar a participação não estatal nas decisões cotidianas. Há também uma ampliação global na integração entre os interesses ambientais e sociais, de onde decorre a instituição de ações e políticas socioambientais (BRANNSTROM, 2005).

No caso da Política Agrícola, ainda há necessidade de ampliação do compartilhamento do poder decisório entre o Estado e entidades não estatais, reforçando a postura menos centralizadora do governo federal. Tal fato incentivaria os atores a negociar novas regras e relações institucionais, desenvolver novas normas de concepção e caminhar para a elaboração de intervenções políticas legítimas. Entretanto, para tais avanços, há necessidade da ampliação do compartilhamento das informações e instalação de adequadas arenas de discussão, que garantam a ampla participação.

\section{Aprendizados oriundos da análise de três políticas socioambientais brasileiras}

A análise da Política Nacional de Meio Ambiente, da Política Nacional de Recursos Hídricos e da Política Agrícola ressalta a importância estatal e não estatal nos processos de formulação e na implementação de políticas socioambientais no Brasil. A caracterização reforça a influência dos processos de descentralização e a participação pública na tomada de decisões. Dessa forma, releva-se pontuar a relevância de adoção de um conceito de política 
pública que inclua a participação não estatal. Mostra-se adequado então o emprego do conceito que considera política pública como um processo resultante dos conflitos de interesses e dos arranjos feitos nas esferas de poder que perpassam as instituições do Estado e da sociedade como um todo para que se tomem decisões (LAUMANN et al., 1991; VAZ, 2007). No Brasil, o resultado destas disputas é, quase sempre, expresso na forma de uma lei sancionada pelo Presidente da República, após um projeto de lei ter sido debatido ao longo do processo legislativo e transformado em lei aprovada pelo Congresso Nacional.

A análise das três políticas socioambientais evidencia a existência de características comuns que relacionam-se também aos traços da administração pública brasileira: (i) ausência de quadro técnico e gestor qualificado; (ii) desvio de função de servidores públicos; (iii) pessoalização; (iv) desarticulação interinstitucional; (v) pulverização de informação e processos interligados e (vi) sobreposição das etapas de identificação do problema, formulação e implementação das políticas públicas (MACHADO, 2000; SANTILLI, 2005). É notável ainda a importância do contexto histórico e do momento político em que os movimentos se inserem, podendo ser responsáveis pela viabilização, ou não, da formulação e da implementação de uma política pública.

Da análise dos processos de formulação e de implementação das políticas públicas selecionadas, pode-se extrair também aprendizados para uma nova ação em prol da formulação e da implementação de outras políticas públicas a serem postas em execução no território brasileiro. Dentre eles, destaca-se a identificação do momento político favorável para o desencadeamento do processo. $\mathrm{O}$ alinhamento entre o momento político e a intensificação da divulgação de informações poderia potencializar o processo, levando à mobilização pública. Como colocado por Castells (2000), a disponibilidade de informação é o catalisador das mudanças comportamentais da sociedade contemporânea.

Essas mudanças comportamentais da sociedade contemporânea se materializam a partir da democratização da informação, que é um ponto crucial para o aprimoramento dos instrumentos normativos e do arcabouço institucional. Além disso, é fundamental que a possível solução se traduza na linguagem da ação pública, caso contrário inviabiliza a admissão de estratégias nesse sentido.

A comparação entre os processos de formulação da PNMA e da PNRH ilustra os efeitos da proposição de políticas em que não há plena inclusão das partes afetas ao tema.
Não se trata de elaborar uma proposta a partir das ideias e dos conceitos de um dos ministérios, para posterior validação dos demais. Faz-se necessário que mesmo a proposta seja resultante de amplo debate social, indo além da esfera estatal, uma vez que a participação voluntária da sociedade será o diferencial para que se tenha sucesso na empreitada.

Os conflitos e discordâncias são inerentes ao processo decisório. Assim, seria preciso garantir que tais conflitos fossem conduzidos em um ambiente de diálogo. E que conceitos, fundamentos e princípios da política sejam resultado da emersão das discussões privilegiadas pela descentralização.

Desde o início da descentralização estatal, na década de 1980, os conceitos de organização social e governança passaram a privilegiar organizações não hierárquicas, a exemplo do que vimos na implementação da PNRH. A administração deixou de ser controlada por uma inteligência central, e passou a contemplar a multiplicidade. Entretanto, as três políticas brasileiras analisadas apresentam níveis diferenciados de descentralização. Independente do nível de descentralização, a formulação e a implementação de políticas socioambientais, além de propor-se a solucionar os problemas centrais às quais destinam-se, são exercício de democracia que tendem a fortalecer a capacidade participativa e decisória da sociedade, levando a um amadurecimento da mesma.

A criação dos comitês de bacia permitiu a instalação de arenas de discussão nas quais, a partir de referenciais explícitos pela PNRH e pelos Planos de Bacia, os atores estatais e não estatais puderam iniciar processos de discussão e negociação. O diferencial desta arena é a redução da distância física entre os atores, o que promove a intensificação de relações pessoais decorrentes do cotidiano compartilhado. Esse fenômeno também foi documentado por Kenis (1991) que, ao discutir a governança em três países, destacou a importância da reduzida distância física na definição das alianças prioritárias entre membros da indústria. Na concepção da Política Nacional de Meio Ambiente (PNMA), arenas equivalentes foram previstas. Entretanto, sua materialização, por meio do CONAMA, se deu em âmbito muito menos democrático para os que demandam e questionam as decisões deste Conselho. Isso porque, ainda que o CONAMA seja constituído por diversos atores, sua maioria é estatal e o acesso público ao mesmo permanece restrito. Crítica semelhante foi feita ao CNPA. A governança deve garantir que o atendimento aos objetivos específicos e demandas de uma instituição não prejudique 
ou degenere os esforços e objetivos de outra. Tal como documentamos neste estudo, Fornazari (2006), estudando políticas públicas brasileiras de outros domínios, destacou os desafios da articulação entre políticas setoriais para que elas se tornem políticas de Estado. Para que se superem as dificuldades decorrentes da fragmentação do arcabouço institucional, faz-se necessário que o posicionamento divergente seja substituído pelo colaborativo.

O presente estudo nos permite evidenciar que algumas das dificuldades averiguadas durante a concepção e a implementação de políticas públicas advêm da fraca tradição brasileira de estabelecer políticas e/ou planos de ação que sejam capazes de trabalhar com cenários desejáveis, porém realistas, no planejamento das questões socioambientais. As informações analisadas e apresentadas no presente estudo reforçam a opinião de que o entendimento do processo político é útil, tanto retrospectivamente quanto prospectivamente, para entendermos falhas e sucessos políticos e podermos planejar a implementação de políticas futuras. A partir das análises, pode-se extrair como aprendizado para a formulação e a implementação de uma política pública socioambiental: (i) o processo precisaria valer-se do momento político favorável; (ii) há necessidade de tradução das soluções propostas em uma linguagem de ação pública; (iii) há necessidade de ampla divulgação do problema para que o processo de mobilização e participação cível e institucional reflita a amplitude do problema; (iv) a

\section{Referências}

ABERS, R. N.; JORGE, K. D. Descentralização da gestão da água: por que os comitês de bacia estão sendo criados? Ambiente \& Sociedade, v. 8, p. 99-124, 2005.

; KECK, M. E. Mobilizing the state: the erratic partner in Brazil's participatory water policy. Politics \& Society, v. 37 , n. 2, p. 289-314, 2009.

ABRH - ASSOCIAÇÃO BRASILEIRA DE RECURSOS HÍDRICOS. Politica e sistema nacional de gerenciamento de recursos hídricos. São Paulo: ABRH - Associação Brasileira de Recursos Hidricos, 1995. 64 p. Relatório técnico.

ACSELRAD, H. Políticas ambientais e construção democrática. In: VIANA, G.; SILVA, M.; DINIZ, N. (Eds.). O desafio da sustentabilidade: um debate socioambiental no Brasil. São Paulo: Editora Fundação Perseu Abramo, 2001. p. 75-96. elaboração da proposta de uma política pública precisaria ser resultante de amplo debate entre atores estatais e não estatais, reforçando também a importância da democratização das informações sobre o tema; (v) o estabelecimento de conceitos, fundamentos e princípios precisaria refletir os resultados dos debates e não a opinião de um ou poucos atores envolvidos no processo, caso contrário, incorre-se no risco de esvaziamento da política; (vi) da mesma forma, a formação do conselho precisaria refletir a ampla gama de atores afetos ao tema; (vii) há necessidade de promover e fomentar atitudes colaborativas - o estabelecimento de debates construtivos poderia se estabelecer a partir do fomento ao estabelecimento de um ambiente de confiança, por exemplo, com a divulgação de informações transparentes e atualizadas; (viii) há necessidade de se reduzir a distância física entre atores por meio da instalação de arenas de discussão, e (ix) há necessidade de se promover a superação da fragmentação do arcabouço institucional.

\section{Agradecimentos}

$\mathrm{O}$ autor gostaria de agradecer às contribuições advindas de dois revisores anônimos. Este estudo foi parcialmente financiado pela linha de apoio financeiro do Banco Real Desenvolvimento Sustentável e Políticas Públicas.

AICHER, C.; DIESEL, V. Políticas ambientais na Europa: leitura a partir da perspectiva do advocacy coalition framework. Revista Extensão Rural, v. XI, 2004.

ALVES, E. R. A. Reflexões sobre política agrícola. Revista de Economia e Sociologia Rural, v. 31, n. 2, p. 91-102, 1993. ANA - AGÊNCIA NACIONAL DE ÁGUAS. Evolução da organização e implementação da gestão de bacias no Brasil. 2002. $24 \mathrm{p}$.

. Plano nacional de recursos hídricos. Síntese executiva. 2006. $135 \mathrm{p}$.

ARAÚJO, M. M.; ROCHA, R. M. L.; SILVA, B. G. Gestão ambiental participativa: o planejamento urbano-ambiental sustentável a partir das bacias hidrográficas. In: CONGRESSO NACIONAL DO CONPEDI: DIREITO, SOCIOBIODIVER- 
SIDADE E SOBERANIA NA AMAZÂONIA, 15., 2007. Anais... Florianópolis, SC: Fundação Boiteaux, 2007. p. 1-18.

BALSAN, R. Impactos decorrentes da modernização da agricultura brasileira. Campo-Território: Revista de Geografia Agrária, v. 1, n. 2, p. 123-151, 2006.

BANERJEE, O.; MACPHERSON, A. J.; ALAVALAPATI, J. Toward a policy of sustainable forest management in Brazil: A historical analysis. The Journal of Environment Development, v. 18, n. 2, p. 130-153, 2009.

BORGES, S. H. et al. Uma análise geopolítica do atual sistema de unidades de conservação na Amazônia Brasileira. Política Ambiental, v. 4, p. 3-42, 2007.

BRANNSTROM, C. Environmental policy reform on northeastern Brazil's agricultural frontier. Geoforum, v. 36, n. 2, p. 257-271, 2005.

BRASIL. Lei n. 6.938 de 31 de agosto de 1981. Dispõe sobre a Política Nacional do Meio Ambiente, seus fins e mecanismos de formulação e aplicação, e dá outras providências. Diário Oficial da República Federativa do Brasil, Brasilia, DF, 2 set. 1981, p. 16509.

Constituição da República Federativa do Brasil. Senado, 5 out. 1988.

Lei n. 8.171, de 17 de janeiro de 1991. Dispõe sobre a Política Agrícola. Diário Oficial da República Federativa do Brasil, Brasilia, DF, 18 jan. 1991.

Lei n. 9.433, de 8 de janeiro de 1997a. Institui a Política Nacional de Recursos Hídricos, cria o Sistema Nacional de Gerenciamento de Recursos Hídricos, regulamenta o inciso XIX do art. 21 da Constituição Federal, e altera o art. $1^{\circ}$ da Lei $\mathrm{n}^{\circ} 8.001$, de 13 de março de 1990, que modificou a Lei $\mathrm{n}^{\circ}$ 7.990, de 28 de dezembro de 1989. Diário Oficial da República Federativa do Brasil, Brasilia, DF, 9 jan 1997a.

. Mensagem n. 870, de 6 de agosto de 1997. 1997b.

Brasil Lei $\mathrm{n}^{\circ}$ 9.984, de 17 de julho de 2000. Dispõe sobre a criação da Agência Nacional de Águas - ANA, entidade federal de implementação da Política Nacional de Recursos Hídricos e de coordenação do Sistema Nacional de Gerenciamento de Recursos Hídricos, e dá outras providências. Diário Oficial da República Federativa do Brasil, Brasília, DF, p. 1,.18 jul. 2000b.

. Decreto ${ }^{\circ} 4.623$. Dispõe sobre os Conselhos Nacional de Política Agrícola - CNPA e Deliberativo da Política do Café - CDPC, vinculados ao Ministério da Agricultura, Pecuária e Abastecimento, e dá outras providências. Diário
Oficial da República Federativa do Brasil, Brasília/DF, n. 57, p. 3, 21 mar. 2003.

Câmara dos Deputados: Legislação Informatizada. Disponível em: <http://www2.camara.gov.br/legislacao/legin. $\mathrm{html} /$ visualizarNorma.html?ideNorma $=365106 \&$ PalavrasDes taque $=>$. Acesso em: 20 set 2009 .

BRESSER-PEREIRA, L. C. Problemas da agricultura brasileira e suas causas. Journal of Inter-American Studies, v. 6, n. 1, p. 43-55, 1964.

Gestão do setor público: estratégia e estrutura para um novo Estado. In: ; SPINK, P. (Eds.). Reforma do Estado e administração pública gerencial. Rio de Janeiro: FGV, 1999. p. 21-38.

CAPOBIANCO, J. P. CONAMA: um espaço ameaçado de extinção. Revista Debates Socioambientais, v. II, n. 6, p. 9-11, 1997.

CARVALHO, M. A.; SILVA, C. R. L. Preços mínimos e estabilização de preços agrícolas. Revista de Economia Política, v. 13, n. 1, p. 52-63, 1993.

CASTELlS, M. A sociedade em rede. 8. ed. São Paulo: Paz \& Terra, 2000. $698 \mathrm{p}$.

CASTRO, J. E. Water governance in the twentieth-first century. Ambiente \& Sociedade, v. 10, p. 97-118, 2007.

CONCEIÇÃO, P. H. Z.; CONCEIÇÃO, J. C. P. R. Uma contribuição metodológica para análise de decomposição da produtividade total dos fatores na agricultura brasileira. In: INTERNACIONAL PENSA CONFERENCE ON AGRI-FOOD CHAINS/NETWORKS ECONOMICSAND MANAGEMENT, 5.; CONGRESSO BRASILEIRO DE ECONOMIA E SOCIOLOGIA RURAL, 42., 2005. Anais... Ribeirão Preto, 2005.

COSTA, M. A. M. Reflexões sobre a política participativa das águas: o caso do CBH Velhas (MG). Dissertação (Mestrado em Geografia) - Departamento de Geografia, Universidade Federal de Minas Gerais. 134 p. Belo Horizonte, 2008.

CUNHA, A. A política agrícola comum na era da globalização. Coimbra, Portugal: Almedina, 2004. 291 p.

DIAS, G. L. D. S. O Estado e o agro em tempos de liberalização. Revista de Economia e Sociologia Rural, v. 44, p. 341-354, 2006.

DRUMMOND, J.; BARROS-PLATIAU, A. F. G. Brazilian environmental laws and polices, 1934-2002: a critical overview. Law \& Policy, v. 28, n. 1, p. 83-108, 2006. 
DYE, T. D. Understanding Public Policy. New Jersey, Prentice-Hall, 1984.

ÉBOLI, E. Ex-secretário de Marina Silva faz críticas à postura do governo sobre meio ambiente. Separata de: $O G L O B O$, p.17, 2008.

ELOBELD, A.; BEGHIN, J. Multilateral trade and agricultural policy reforms in sugar markets. Journal of Agricultural Economics, v. 57, n. 1, p. 23-48, 2006.

FORMIGA-JOHNSSON, R. M.; KEMPER, K. E. Institutional and policy analysis of river basin management in the Alto-Tietê River Basin, São Paulo, Brazil. Washington, DC: The World Bank, 2005a. 53 p. Relatório técnico.

Institutional and policy analysis of river basin management in the Jaguaribe River Basin, Ceará, Brazi.Washington, DC: The World Bank, 2005b. 42 p. Relatório técnico.

FORNAZARI, F. K. Instituições do Estado e políticas de regulação e incentivo ao cinema no Brasil: o caso Ancine e Ancinav. Revista de Administração Pública, v. 40, n. 4, p. 647-677, 2006.

HESPANHOL, I. Um novo paradigma para a gestão de recursos hídricos. Estudos Avançados, v. 22, p. 131-158, 2008.

HUBERT, G.; PEREIRA, J. S.; LANNA, A. E. L. Os novos instrumentos de planejamento do sistema francês de gestão de recursos hídricos: I - Apresentação e análise. Revista Brasileira de Recursos Hídricos, v. 7, n. 2, p. 81-107, 2002.

IBAMA - INSTITUTO BRASILEIRO DO MEIO AMBIENTE E DOS RECURSOS NATURAIS RENOVÁVEIS. RQMA 2007: Relatório da Qualidade do Meio Ambiente. 2007. 2 p.INCRA - INSTITUTO NACIONAL DE COLONIZAÇÃO E REFORMA AGRÁRIA. Relatório de gestão: Exercício 2008. 2009a. 407 p.

. Resumo das atividades do INCRA - 1995/1999. 2009b.

IORIS, A. A. R. Águas que não correm mais pro mar. Interações, v. 9, p. 9-17, 2008.

.Water reforms in Brazil: opportunities and constraints.

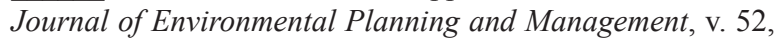
n. 6, p. 813-832, 2009.

KENIS, P. The precontitions for Policy Networks: some findings from a three-country study on industrial restructuring. In: MARIN, B.; MAYNTZ, R. (Eds.). Policy networks: Empirical evidence and theoretical considerations. Frankfurt: Campus Verlag, 1991. p. 297-330.

LANNA, A. E. L.; PEREIRA, J. S.; HUBERT, G. Os novos instrumentos de planejamento do sistema francês de gestão de recursos hídricos: II - Reflexões e propostas para o Brasil. Revista Brasileira de Recursos Hídricos, v. 7, n. 2, p. 109120, 2002.

LAUMANN, E. O. et al. Organizations in political action: Representing interest in national policy making. In: MARIN, B.; MAYNTZ, R. (Eds.). Policy networks: Empirical evidence and theoretical considerations. Frankfurt: Campus Verlag, 1991. p. 63-95.

LEMOS, M. C.; OLIVEIRA, J. L. F. Water reform across the state/society divide: The case of Ceará, Brazil. International Journal of Water Resources Development, v. 21, n. 1, p. 133147, 2005.

LOPES, I. V.; LOPES, M. R.; BARCELOS, F. C. Das políticas de substituição das importações à agricultura moderna do Brasil. Revista Política Agrícola, v. XVI, n. 4, p. 52-85, 2007.

LUCHINI, A. M.; SOUZA, M. D.; PINTO, A. L. Aportes e limites da perspectiva de redes de políticas públicas $-\mathrm{O}$ caso da Política Nacional de Recursos Hídricos. Caderno de Pesquisas em Administração, v. 10, p. 87-94, 2003.

MACHADO, C. J. S. A questão ambiental brasileira, uma análise sociológica do processo de formação do arcabouço jurídico-institucional. Revista de Estudos Ambientais, v. 2, n. 2-3, p. 5-20, 2000.

Um quadro sinóptico do processo de formação do arcabouço jurídico-institucional ambiental brasileiro. Revista Internacional de Estudos Políticos, v. 3, n. 1, p. 95-121, 2001.

Recursos hídricos e cidadania no Brasil: limites, alternativas e desafios. Ambiente \& Sociedade, v. VI, n. 2, p. 121-136, 2003a.

. A gestão francesa de recursos hídricos: descrição e análise dos princípios jurídicos. Revista Brasileira de Recursos Hidricos, v. 8, n. 4, p. 31-47, 2003 b.

O mundo da administração pública das águas do Estado do Rio de Janeiro segundo o olhar de um antropólogo. Horizontes Antropológicos, v. 12, p. 171-190, 2006.

; MIRANDA, N.; PINHEIRO, A. A. S. A nova aliança entre Estado e sociedade na administração da coisa pública: descentralização e participação na Política Nacional de Recursos Hídricos. In: (Ed.). Gestão de águas doces. Rio de Janeiro: Interciência, 2004. p. 3-38.

MEDEIROS, R. J. A proteção da natureza: das estratégias internacionais e nacionais às demandas locais. Tese (Doutorado em Ciências) - Departamento de Geografia, Universidade do Estado do Rio de Janeiro. 391 p. Rio de Janeiro, 2003. 
. Evolução das tipologias e categorias de áreas protegidas no Brasil. Ambiente \& Sociedade, v. 9, p. 41-64, 2006.

MELLO, N. A. E a política agrícola transforma-se em instrumento do desenvolvimento sustentável. Revista Nera, v. 11, n. 12, p. 68-85, 2008.

MILARÉ, É. Direito do ambiente: a gestão ambiental em foco - doutrina, jurispudência, glossário. 5. ed. São Paulo: Editora Revista dos Tribunais, 2007. $1280 \mathrm{p}$.

MMA-MINISTÉRIO DO MEIO AMBIENTE, DOS RECURSOS HÍDRICOS E DAAMAZÔNIA LEGAL. Plano Nacional de Recursos Hídricos. Brasília, DF, 2006.

MONOSOWSKI, E. Políticas ambientais e desenvolvimento no Brasil. Cadernos FUNDAP, v. 9, n. 16, p. 15-24, 1989.

NAGEL, S. S. The policy studies handbook. Lexington: Lexington Books, 1980.

O GLOBO. Secretaria de Meio Ambiente do PT divulga nota criticando a política ambiental do governo Lula. Separata de: $O$ GLOBO, v., p.11, 2009.

PARSONS, W. Public Policy: An introduction to the theory and practice of policy analysis. 1. ed. Northampton: Edward Elgar, 1995. $675 \mathrm{p}$.

PORRO, R.; SERRAO, A.; CORNELIUS, J. P. The Amazon initiative: A multidisciplinary, international consortium for prevention, mitigation and reduction of resource degradation. Forestry Chronicle, v. 81, n. 3, p. 337-341, 2005.

PORTO, M.; PORTO, R. L. L.; AZEVEDO, L. G. T. A participatory approach to watershed management: The Brazilian system. Journal of the American Water Resources Association, v. 35 , n. 3, p. $675-683,1999$.
PORTO, R. L.; PORTO, M. F. A. planning as a tool to deal with extreme events - The new Brazilian Water Resources Management System. Water International, v. 27, n. 1, p. 14-19, 2002.

SANTILLI, J. Socioambientalismo e novos direitos: proteção jurídica à diversidade biológica e cultural. São Paulo: Peirópolis, $2005.303 \mathrm{p}$.

SORRENSEN, C. Potential hazards of land policy: Conservation, rural development and fire use in the Brazilian Amazon. Land Use Policy, v. 26, n. 3, p. 782-791, 2009.

SOUSA, M. M. M. Reforma neoliberal e privatização da economia Brasileira - justificativas x resultados: o sistema Telebrás. 2005. 86 p. Monografia de Bacharelado em Economia - Departamento de Economia, Administração e Ciências Contábeis, Universidade Católica de Pernambuco, Recife,

TÁVORA, F. L. A política agrícola brasileira: análise e histórico recente. Revista de Informação Legislativa, v. 40, n. 157, p. 153-207, 2003.

TEIXEIRA, E. C. O papel das políticas públicas no desenvolvimento local e na transformação da realidade. AATR-BA. 2002. 11 p. Relatório técnico.

UNO - UNITED NATIONS ORGANIZATION. The Dublin Statement on Water and Sustainable Development. 2009.

VAZ, L. G. D. Políticas públicas. Revista "Nova Atenas" de Educação Tecnológica, v. 10, n. 1, p. 1-7, 2007.

VIOLA, E. O. O regime internacional de mudança climática. Revista Brasileira de Ciências Sociais, v. 17, n. 50, p. 25-46, 2002. 